\title{
A flood risk curve development for inundation disaster considering spatio-temporal rainfall distribution
}

\author{
T. Tanaka, Y. Tachikawa, and K. Yorozu \\ Graduate School of Engineering, Kyoto University, Kyoto, Japan \\ Correspondence to: T. Tanaka (tanaka.tomohiro.65m@st.kyoto-u.ac.jp)
}

Received: 11 March 2015 - Accepted: 11 March 2015 - Published: 11 June 2015

\begin{abstract}
To manage flood disaster with an exceeding designed level, flood risk control based on appropriate risk assessment is essential. To make an integrated economic risk assessment by flood disaster, a flood risk curve, which is a relation between flood inundation damage and its exceedance probability, plays an important role. This research purposes a method to develop a flood risk curve by utilizing a probability distribution function of annual maximum rainfall through rainfall-runoff and inundation simulations so that risk assessment can consider climate and socio-economic changes. Among a variety of uncertainties, the method proposed in this study considered spatio-temporal rainfall distributions that have high uncertainty for damage estimation. The method was applied to the Yura-gawa river basin $\left(1882 \mathrm{~km}^{2}\right)$ in Japan; and the annual economic benefit of an existing dam in the basin was successfully quantified by comparing flood risk curves with/without the dam.
\end{abstract}

\section{Introduction}

A flood risk curve, a relation between the annual economic flood inundation damage and its exceedance probability, is essential information to establish an effective river planning to cope with flood disasters. In most basins, however, it is difficult to estimate a PDF (probability distribution function) of economic loss from disaster record because of few number of flood disaster data; thus estimating a PDF of the economic damage through rainfall-runoff and inundation simulations is an effective method.

One of the major approaches to estimate a PDF of the economic damage due to flood is to give a number of generated hydrographs on the main stream from its probability function and obtain a PDF of inundation depth or the economic damage through inundation simulations (Apel et al., 2006; Thieken et al., 2014). Another approach proposed here is to estimate a PDF of an annual maximum economic damage from that of annual maximum rainfall information through a rainfall-runoff model and an inundation model. A flood risk curve development from a PDF of rainfall has two advantages; one is to automatically consider the correlation among flood discharges on several tributaries through rainfall-runoff simulations, and the other is to consider the non-stationarity of rainfall characteristics due to climate change by giving a
PDF of rainfall under climate change scenarios. For comprehensive flood risk assessment that considers climate change impact, this research presents a method to estimate a flood risk curve from a PDF of annual maximum rainfall information.

In converting a rainfall PDF into a PDF of the economic damage, it is important to consider the uncertainty of spatiotemporal rainfall distributions (hereafter referred to as rainfall patterns). This study treats the uncertainty of the rainfall patterns by incorporating typical rainfall patterns which happened in a study basin. The developed method was applied to the Yura-gawa river basin; and annual economic benefit of an existing dam in the basin was quantified by comparing flood risk curves with/without the dam operation.

\section{Framework of development of a flood risk curve}

In some river basins in Japan, a design flood is determined from a PDF of the annual maximum rainfall through a rainfall-runoff model using the Synthesis Probability Method (SPM). The method was developed to consider the uncertainty of spatio-temporal rainfall distributions. The mathematical background of this method is explained by Shiiba and Tachikawa (2013). In this study, the SPM is extended to 
estimate a flood risk curve. The assumptions to estimate a flood risk curve are as follows:

1. A total amount of rainfall in a pre-determined rainfall duration is independent from rainfall patterns.

2. For a fixed rainfall pattern, the economic damage monotonically increases as the total amount of rainfall increases.

According to the first assumption, the rainfall intensity on the location $x, y$ at time $\operatorname{tr}(x, y, t)$ is expressed as;

$r(x, y, t)=r_{\mathrm{a}} \xi(x, y, t),(x, y) \in A, 0 \leq t \leq T_{\mathrm{r}}$

where, $A$ represents a region of a study basin: $T_{\mathrm{r}}$ is the rainfall duration: $r_{\mathrm{a}}$ is a total amount of basin rainfall during $T_{\mathrm{r}}$. $\xi(x, y, t)$ is the rainfall pattern, which is normalized to satisfy;

$\iiint_{A}\left(\int_{0}^{T_{\mathrm{r}}} \xi(x, y, t) \mathrm{d} t\right) \mathrm{d} x \mathrm{~d} y=S$

where, $S$ is the area of a study basin. The other two assumptions are as follows:

3. The total number of the rainfall pattern $\xi(x, y, t)$ is limited to $N$ patterns, and the occurence probability for the $i$ th rainfall pattern $\xi_{i}(x, y, t)$ is $p_{i}$.

4. The rainfall events that cause the economic damage follow the Poisson process with the occurrence ratio $\mu$. The total amount of a rainfall event in the duration $T_{\mathrm{r}}$ follows a CDF $G_{R_{\mathrm{a}}}\left(r_{\mathrm{a}}\right)$.

Based on the assumptions 1,2 and 3, the probability with which the economic damage $M$ exceeds a certain economic damage $m_{1} \operatorname{Pr}\left[M>m_{1}\right]$ is obtained as follows;

$$
\begin{aligned}
\operatorname{Pr}\left[M>m_{1}\right] & =\sum_{i=1}^{N} p_{i} \operatorname{Pr}\left[M>m_{1} \mid \xi=\xi_{i}\right] \\
& =\sum_{i=1}^{N} p_{i} \operatorname{Pr}\left[r_{\mathrm{a}}>r_{\mathrm{a}, i}\left(m_{1}\right)\right]
\end{aligned}
$$

where, $r_{\mathrm{a}, i}\left(m_{1}\right)$ is a rainfall amount that causes the economic damage $m_{1}$ for the $i$ th rainfall pattern. $r_{\mathrm{a}, i}(0)$ is defined as the rainfall amount that causes no economic damage. The left hand side of Eq. (3) indicates the exceedance probability of the economic damage $M$, thus, given the CDF of $M$ as $G_{M}(m)$, Eq. (3) can be rewritten as follows;

$$
\begin{aligned}
1-G_{M}(m) & =\sum_{i=1}^{N} p_{i} \operatorname{Pr}\left[r_{\mathrm{a}}>r_{\mathrm{a}, i}\left(m_{1}\right)\right] \\
& =\sum_{i=1}^{N} p_{i}\left(1-G_{R_{\mathrm{a}}}\left(r_{\mathrm{a}, i}(m)\right)\right)
\end{aligned}
$$

According to the assumption 4, the economic damage follows the compound Poisson process with the occurrence ratio $\mu$ and the exceedance probability $G_{M}(m)$. Accordingly, the CDF of the annual maximum economic damage $F_{M}(m)$ is given as;

$F_{M}(m)=\exp \left[-\mu \Delta t\left(1-G_{M}(m)\right)\right]$

where, $\Delta t$ represents 1 year. Substituting Eq. (4) into the right hand side of Eq. (5),

$$
\begin{aligned}
F_{M}(m) & =\exp \left[-\mu \Delta t \sum_{i=1}^{N} p_{i}\left(1-G_{R_{\mathrm{a}}}\left(r_{\mathrm{a}, i}(m)\right)\right)\right] \\
& =\sum_{i=1}^{N} \exp \left[-\mu \Delta t\left(1-G_{R_{\mathrm{a}}}\left(r_{\mathrm{a}, i}(m)\right)\right)\right]^{p_{i}}
\end{aligned}
$$

is derived. Assumption 4 indicates that $F_{R_{\mathrm{a}}}\left(r_{\mathrm{a}}\right)$, the CDF of the annual maximum rainfall $r_{\mathrm{a}}$ is expressed as;

$$
F_{R_{\mathrm{a}}}\left(r_{\mathrm{a}}\right)=\exp \left[-\mu \Delta t\left(1-G_{R_{\mathrm{a}}}\left(r_{\mathrm{a}}\right)\right)\right]
$$

Substituting Eq. (7) into Eq. (6), $F_{M}(m)$ is finally obtained as;

$$
F_{M}(m)=\prod_{i=1}^{N} F_{R_{\mathrm{a}}}\left(r_{\mathrm{a}, i}(m)\right)^{p_{i}}
$$

Through Eq. (8), the CDF of the annual maximum economic damage is obtained from that of the annual maximum rainfall. Equation (8) indicates that $F_{M}(m)$ is a weighted geometric mean of the non-exceedance probability of the corresponding rainfall amounts.

The concrete procedure to obtain $F_{M}(m)$ from Eq. (8) consists of following steps:

1. to determine the rainfall duration $T_{\mathrm{r}}$ that is dominant for flood peak discharge;

2. to obtain the distribution of the annual maximum basin rainfall $F_{R_{\mathrm{a}}}\left(r_{\mathrm{a}}\right)$ by the frequency analysis;

3. to prepare the typical $N$ rainfall patterns from the past observed rainfall record;

4. to obtain the normalized spatio-temporal rainfall pattern $\xi_{i}(x, y, t)(i=1,2, \ldots, N)$ by normalizing rainfall intensity of the $i$ th rainfall event $r_{i}(x, y, t)$ using Eq. (2);

5. for each rainfall pattern, to prepare a rainfall event with total rainfall amount $r_{\mathrm{a}}$ by multiplying $r_{\mathrm{a}}$ by $\xi_{i}(x, y, t)$;

6. to obtain a spatial distribution of runoff and river dishcarges over a study basin caused by the $i$ th rainfall pattern with the total rainfall amount $r_{\mathrm{a}}$ through a rainfallrunoff model;

7. to obtain a spatial distribution of inundation depth using an inundation model with the runoff/discharges distribution as the boundary condition; 
8. the economic damage is estimated using an estimated inundation depth and a spatial distribution of the asset of the study basin; and

9. to obtain a relation between total rainfall amount $r_{\mathrm{a}}$ and the economic damage $m$ for the rainfall pattern $i$. $r_{\mathrm{a}, i}(m)(i=1,2, \ldots, N)$ represented by the thick lines in Fig. 1 are derived by repeating Steps 5 to 8 with increasing the rainfall amount $r_{\mathrm{a}}$.

Giving the occurrence probability of the $i$ th rainfall pattern $p_{i}, F_{M}(m)$ is obtained through Eq. (8).

\section{Rainfall-runoff model and inundation model}

To realize the above flood risk curve development, a rainfallrunoff model and an inundation model is necessary to estimate spatial distributions of flood inundation depth. This study applies a distributed rainfall-runoff model 1K-DHM (Tachikawa and Tanaka, 2013) and an inundation model coupled with the rainfall-runoff model developed by Tanaka et al. (2014).

\subsection{A distributed rainfall-runoff model}

$1 \mathrm{~K}-\mathrm{DHM}$ is a distributed rainfall-runoff model based on a kinematic wave flow approximation that considers surfacesubsurface flow. The elevation and the flow direction was determined using HydroSHEDS (Lehner et al., 2006), the gridbased $1 \mathrm{~km}$ resolution DEM, and the model domain is composed of river-channel cells and slope-runoff cells. A kinematic wave flow equation is used in river-channel cells. Flow from slope-runoff for each cell is modeled by the following two equations, which consider both saturated and unsaturated subsurface flow components (Tanaka et al., 2014):

$\frac{\partial h}{\partial t}+\frac{\partial q}{\partial x}=r$

$q=\left\{\begin{array}{lc}d_{\mathrm{c}} k_{\mathrm{c}}\left(\frac{h}{d_{\mathrm{c}}}\right)^{\beta} i & \left(0 \leq h \leq d_{\mathrm{c}}\right) \\ d_{\mathrm{c}} k_{\mathrm{c}} i+\left(h-d_{\mathrm{c}}\right) k_{\mathrm{a}} i & \left(d_{\mathrm{c}} \leq h \leq d_{\mathrm{a}}\right) \\ \sqrt{i} & \left(d_{\mathrm{a}} \leq h\right) \\ \frac{n_{\mathrm{s}}}{}\left(h-d_{\mathrm{a}}\right)^{m}+\left(h-d_{\mathrm{c}}\right) k_{\mathrm{a}} i+d_{\mathrm{c}} k_{\mathrm{c}} i & \end{array}\right.$

where, $r$ is rainfall intensity; $h$ is water stage; $q$ is discharge per unit slope width; $d_{c}$ is an equivalent water stage to the maximum water content in the capillary pore; $k_{\mathrm{c}}$ is hydraulic conductivity when the capillary pore is saturated; $\beta$ is an exponent parameter that describes the relationship between hydraulic conductivity and saturation; $k_{\mathrm{a}}$ is saturated hydraulic conductivity and $k_{\mathrm{a}}=\beta k_{\mathrm{c}} k_{\mathrm{a}}=\beta k_{\mathrm{c}}$ according to the continuity of the $q-h$ relationship Eq. (10); $d_{\mathrm{a}}$ is the water stage equivalent to the maximum water content in the effective

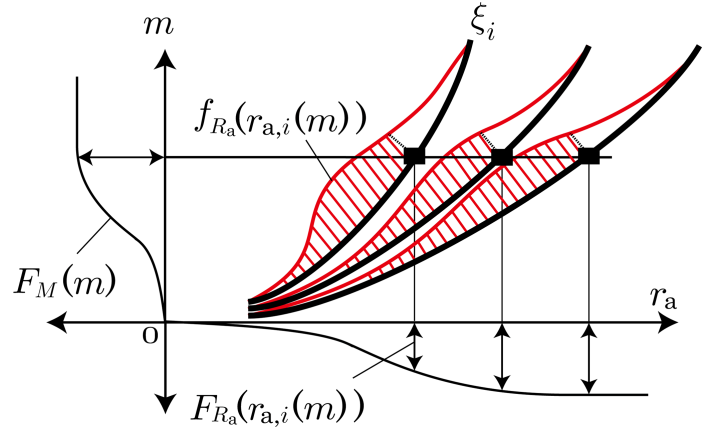

Figure 1. Relations between the non-exceedance probability of the annual maximum rainfall and that of the annual maximum economic damage (the curve bellow the horizontal axis is the CDF of the annual maximum rainfall $F_{R_{\mathrm{a}}}\left(r_{\mathrm{a}}\right)$; the curve on the left of the vertical axis is the CDF of the annual maximum economic damage $F_{M}(m) ; f_{R_{\mathrm{a}}}\left(r_{\mathrm{a}}\right)$ is the PDF of the annual maximum rainfall; and red shaded areas correspond to the non-exceedance probability $\left.F_{M}(m)\right)$.

porosity; and $n_{\mathrm{S}}$ is the Manning's roughness coefficient for overland flow in the slope runoff cells. Equation (10) represents the $q-h$ relationship for the surface and subsurface soil layer.

\subsection{Inundation model coupled with rainfall-runoff simulation}

The inundation model coupled with the rainfall-runoff model (IMCR) was developed to seamlessly give the simulated river discharge and lateral inflow by $1 \mathrm{~K}-\mathrm{DHM}$ to the inundation model. The IMCR realizes the 1-D river routing by the following local inertial equations (Bates et al., 2010);

$\frac{\partial Q}{\partial t}+g A \frac{\partial(h+z)}{\partial x}+\frac{g n^{2}|Q| Q}{R^{4 / 3} A}=0$

$\frac{\partial A}{\partial t}+\frac{\partial Q}{\partial x}=q_{\mathrm{L}}$

where, $Q$ is river discharge, $A$ is the flow cross section area, $R$ is the hydraulic radius, $q_{\mathrm{L}}$ is lateral inflow provided by $1 \mathrm{~K}-\mathrm{DHM}$. Inundation flow from river, which occurs when water level exceeds the elevation of river dikes, is simulated using the 2-D local inertial equations. The lower boundary condition is given as water level at the downstream end of a study area in the innundation model.

\section{Validation of 1K-DHM and IMCR in the Yura-gawa river basin}

\subsection{Rainfall-runoff simulation}

For applying the method to develop a flood risk curve at the Yura-gawa river basin, the performance of 1K-DHM and the 
Table 1. The calibrated parameters of 1K-DHM.

\begin{tabular}{lr}
\hline Parameters & \\
\hline$n_{\mathrm{S}}$ & $0.494 \mathrm{~m}^{-1 / 3} \mathrm{~s}$ \\
$k_{\mathrm{a}}$ & $1.00 \times 10^{-4} \mathrm{~ms}^{-1}$ \\
$d_{\mathrm{a}}$ & $0.603 \mathrm{~m}$ \\
$d_{\mathrm{c}}$ & $0.599 \mathrm{~m}$ \\
$\beta$ & 9.28 \\
\hline
\end{tabular}

IMCR in the basin was validated. The Yura-gawa river basin has been suffered from a number of flood disasters such as the typhoon No. 13 in 1953, the typhoon No. 23 in 2004 and the typhoon 18 in 2013. This study focused on the typhoon 18, which damaged 3855 houses over the basin (Kinki Regional Development Bureau, MLIT, 2013).

The parameters of $1 \mathrm{~K}-\mathrm{DHM}$ were calibrated by the SCEUA algorithm (Duan et al., 1994) to optimize the hydrograph at the Ayabe station (see Fig. 2) for the typhoon No. 23, 2004, which caused the similar damage to the typhoon No. 18, 2013. In the calibration, rain gauge data at 17 stations and dishcarge at the Ayabe station shown in Fig. 2 was used. To consider the effect of dam control by the Ohno dam, the actual dam release flow was given to the model as an upper boundary condition of the rainfall-runoff model. The calibrated parameters are shown in Table 1.

Using the calibrated parameter values, the river discharge for the typhoon No. 18, 2013 was simulated for the model validation. Since rainfall data at some gauges (the black circles in Fig. 2) are deficient, other red gauges were used. Dam release from the Ohno dam was also given to the validation simulation. Figure 3 shows the observed and simulated hydrographs at the Ayabe station, which indicates that the simulated discharge well reproduced the observed one.

\subsection{Inundation simulation}

Inundation was simulated by the IMCR in $100 \mathrm{~m}$ spatial resolution for the shaded area in Fig. 2, inputting the simulated runoff to river channel and river discharge to the boundary of the target area. The Manning's roughness coefficients for the river channel and the flood plain areas were set to 0.045 and 0.05 , respectively. As the boundary condition at the downstream end, the observed water level was given to the IMCR. The estimated spatial distribution of the maximum inundation depth is shown in Fig. 4. In Fig. 4, the thick black line represents the observed inundation area reported by Kinki Regional Development Bureau, MLIT (2013), and the triangle marks show the locations of the bank breaches. At the bank breach locations, the heights of the river dikes were set to $0 \mathrm{~m}$ after overflow starts. We can see that the observed inundation area is well overlapped with the simulated inundation area. The simulated total inundation area is $20.21 \mathrm{~km}^{2}$, which is close to the observed area of $23.03 \mathrm{~km}^{2}$.

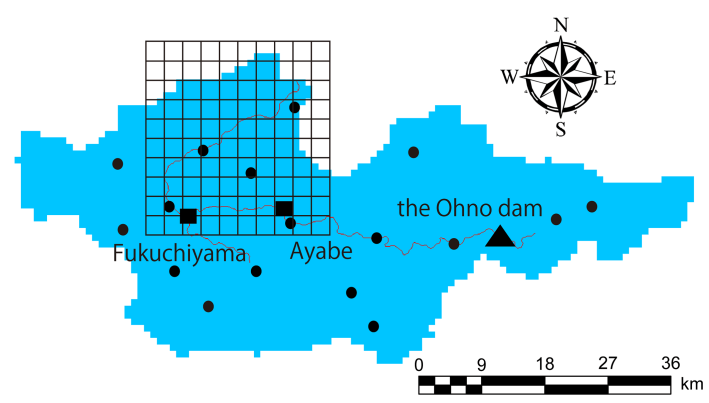

Figure 2. The Yura-gawa river basin and the locations of discharge gauges and rainfall gauges (inundation is simulated in the shaded area; rectangulars are discharge gauges; small circles are rain gauges; and a triangle is the Ohno dam).

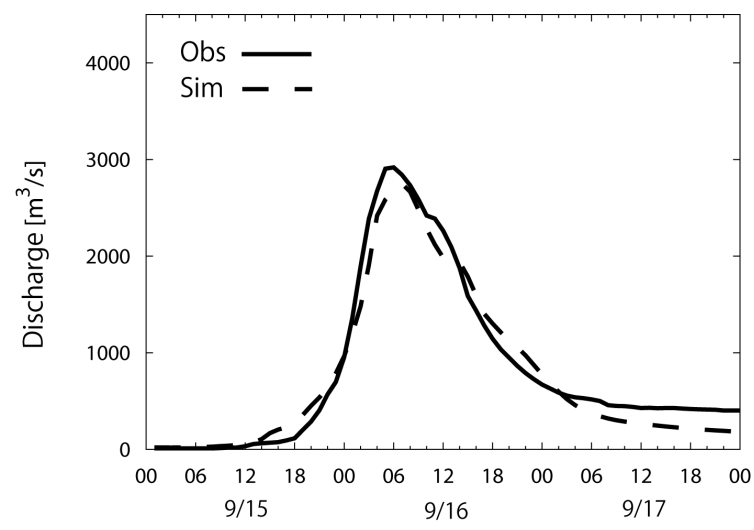

Figure 3. Observed and simulated discharge hydrographs at the Ayabe stations for the typhoon No. 18, 2013 (the solid line is the observed hydrograph; the broken line is the simulated one).

\subsection{Estimation of the economic damage by the typhoon No. 18 in 2013}

The economic damage by the inundation caused by the typhoon No. 18, 2013 was estimated for each $100 \mathrm{~m}$ cell using the spatial distribution of the maximum water depth calculated by the IMCR. To estimate economic loss for each grid cell, the relation between the economic damage and the maximum water depth proposed by MLIT (2005) was used. It was developed for each land use type based on the field surveys for the several past flood disasters in Japan. The economic damage by the typhoon No. 18 for each item is shown in Table 2. The total economic damage was estimated at 58.2 billion Japanese yen, which is similar to the damage caused by the typhoon No. 23, 2004 officially reported as 61.7 billion Japanese yen by MLIT (2004).

\section{Development of flood risk curves of the Yura-gawa river basin}

To develop a flood risk curve using Eq. (8), the CDF of the annual maximum rainfall $F_{R_{\mathrm{a}}}\left(r_{\mathrm{a}}\right)$ was determined by fitting 
Table 2. The estimated economic damage of flood inundation caused by the typhoon 18, 2013.

\begin{tabular}{lr}
\hline Land use & $\begin{array}{r}\text { Damage } \\
\text { [billion Japanese yen] }\end{array}$ \\
\hline Paddy field & 0.29 \\
Farm & 2.62 \\
House & 13.2 \\
Household utensils & 5.03 \\
Office fixed/depreciable assets & 2.30 \\
Golf course & 0.00 \\
Public works facility & 34.8 \\
\hline Total & 58.24 \\
\hline
\end{tabular}

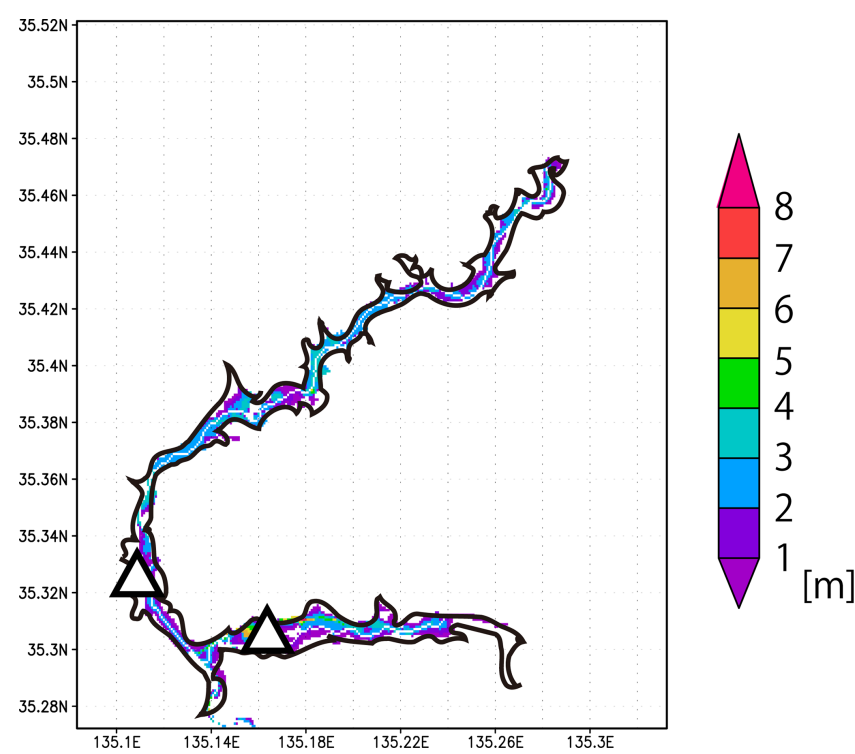

Figure 4. The investigated inundation area (the area surrounded by thick black lines) and the spatial distribution of the maximum water depth for the typhoon No. 18, 2013.

the past annual maximum basin average rainfall in two days to the Gumbel distribution (Stedinger et al., 1993). The relations between the total rainfall amount and the economic damage were estimated for five rainfall patterns $\xi_{i}(x, y, t)$, $(i=1,2, \ldots, 5)$ of the past major floods in 1972, 1982, 1983, 1990 and 1995.

Flood control benefit by the Ohno dam in the Yura-gawa river basin was assessed by developing flood risk curves with/without the dam control. Figure 5 shows the relation between the annual maximum basin rainfall in two days and the economic damage for each rainfall pattern $r_{\mathrm{a}, i}(m)(i=1,2, \ldots, 5)$. Figure 5 indicates that the economic damage values caused by the same amount of the basin rainfall are different for different rainfall patterns, and it is smaller for the relations that consider the dam control.

Finally, flood risk curves with/without dam control developed by Eq. (8) is shown in Fig. 6. They are calculated by tak-

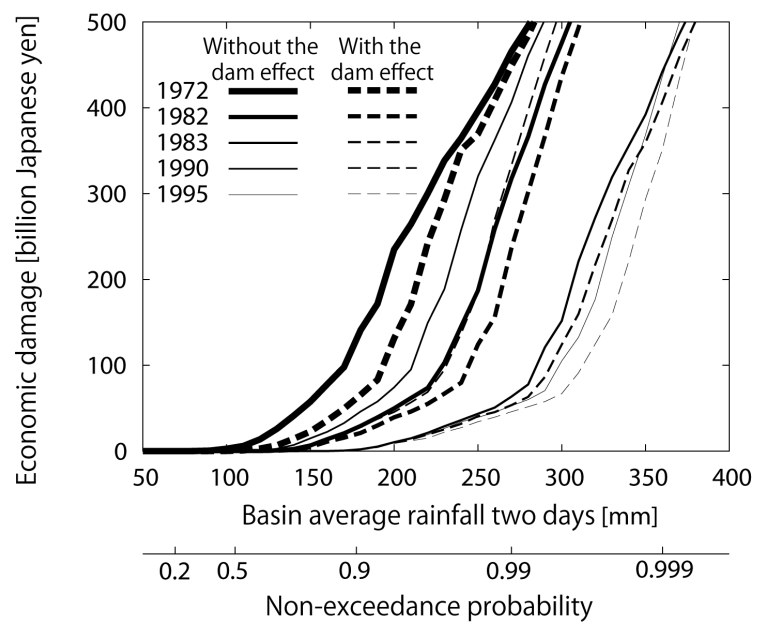

Figure 5. The relation between the basin average total amount of rainfall in two days and the economic damage for five rainfall patterns (solid lines are the relations without dam control; broken lines are the relations with dam control; difference of thickness of the relations indicates difference of rainfall patterns; and the horizontal axis bellow the figure shows the corresponding non-exceedance probability of basin rainfall).

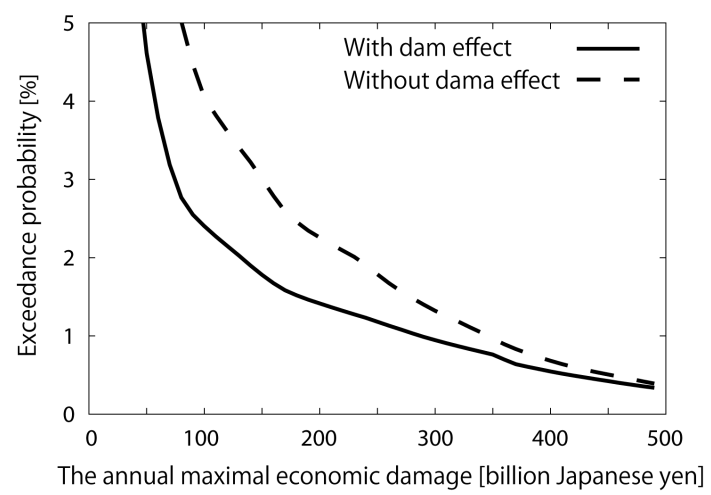

Figure 6. Flood risk curves in the Yura-gawa river basin with/without flood control by the Ohno dam (The solid line is a flood risk curve with dam control; and the broken line is a flood risk curve without dam control).

ing a weighted geometric mean of the non-exceedance probability of the annual maximum rainfall $F_{R_{\mathrm{a}}}\left(r_{\mathrm{a}, i}(m)\right)$, which is shown in the bottom of Fig. 5. The occurrence probability of each rainfall pattern $p_{i}$ is set evenly. Figure 6 indicates that the exceedance probability of the annual maximum economic damage with the dam control is smaller than without dam control, which expresses the effect of the Ohno dam. On the other hand, the difference between the two risk curves becomes smaller for the large economic damage. It is because for large flood exceeding the flood storage capacity, the volume cut off by the dam is much smaller than the total flood volume. By taking an average of the two flood risk curves, the annual expected economic damage without dam control 
was estimated at 14.5 billion Japanese yen, while that with dam control at 8.0 billion Japanese yen.

\section{Conclusions}

This research developed a method to estimate a flood risk curve from a PDF of the annual maximum rainfall utilizing a rainfall-runoff and inundation model considering the variety of rainfall patterns. The proposed method was successfully applied to the Yura-gawa river basin, Japan. As an example of utilization of a flood risk curve, the economic benefit of the existing dam in the basin was assessed by comparing flood risk curves with/without the dam control.

The future studies will focus on expanding the proposed method to consider a probabilistic bank break component and to use rainfall data set under various climate change scenarios.

Acknowledgements. We would like to express our gratitude to Kyoto Prefecture for providing the Ohno dam operation data.

\section{References}

Apel, H., Thieken, A. H., Merz, B., and Bloschl, G.: A probabilistic modelling system for assessing flood risks, Nat. Hazards, 38, 12, 79-100, 2006.

Bates, P. D., Horritt, M. S., and Fewtrell, T. J.: A simple inertial formulation of the shallow water equations for efficient twodimensional flood inundation modeling, J. Hydrol., 387, 33-45, 2010 .
Duan, Q., Sorooshian, S., and Gupta, V. K.: Optimal use of the SCEUA global optimization method for calibrating watershed models, J. Hydrol., 158, 265-284, 1994.

Kinki Regional Development Bureau, Ministry of Land, Infrastructure, Transportation and Tourism (MLIT): Summary report of the typhoon No. 18, 1-10, 2013 (in Japanese).

Lehner, B., Verdin, K., Jarvis, A.: HydroSHEDS Technical Documentation. World Wildlife Fund US, Washington, DC, available at: http://hydrosheds.cr.usgs.gov (last access: 31 January 2015), 2006.

Ministry of Land, Infrastructure, Transportation and Tourism (MLIT): Statistics of the flood disaster damage in Japan, Japan, p. 3, 2004 (in Japanese).

Ministry of Land, Infrastructure, Transportation and Tourism (MLIT): The manual of how to estimate the economic damage by flood disaster in Japan (Proposed), Japan, p. 91, 2005 (in Japanese).

Shiiba, M. and Tachikawa, Y.: Mathematical aspect of synthesis probability method to determine design flood, Journal of JSCE, 69, 101-104, 2013 (in Japanese).

Stedinger, J. R., Vogel, R. M., and Foufoula-Georgiou, E.: Frequency Analysis of Extreme Events, Handbook Hydrology, edited by: Maidment, D. R., McGraw-Hill Professional, New York, 18.16-18.17, 1993.

Tachikawa, Y. and Tanaka, T.: 1K-DHM, available at: http://hywr. kuciv.kyoto-u.ac.jp/products/1K-DHM/1K-DHM.html (last access: 31 January 2015), 2013.

Tanaka, T., Tachikawa, Y., and Yorozu, K.: Development of a floodinundation model nesting a distributed rainfall-runoff model, Journal of JSCE, 70, I_1495-I_1500, 2014 (in Japanese).

Thieken, A. H., Apel, H., and Merz, B.: Assessing the probability of large-scale flood loss events: a case study for the river Rhine, Germany, Journal of Flood Risk Management, doi:10.1111/jfr3.12091, 2014. 